\title{
A UTILIZAÇÃO DE BORRA DE FOSFATO COMO MATÉRIA-PRIMA ALTERNATIVA PARA A FABRICAÇÃO DE TIJOLOS
}

\section{THE USE OF PHOSPHATE SLUDGE AS AN ALTERNATIVE RAW MATERIAL IN THE MANUFACTURING OF BRICKS}

\section{PATRÍCIA DE OLIVEIRA GIFFONI}

Engenheira civil e mestre pelo Programa de Pós-graduação em Saneamento. Meio Ambiente e Recursos Hídricos da Universidade Federal de Minas Gerais

\begin{abstract}
LISÉTE CELINA LANGE
Professora adjunta do Departamento de Engenharia Sanitária e Ambiental da Universidade Federal de Minas Gerais (UFMG). Doutora em Tecnologia Ambiental pela Universidade de Londres - Inglaterra
\end{abstract}

Recebido: 16/12/04 Aceito: 03/03/05

\section{RESUMO}

O resíduo denominado "borra de fosfato" é gerado por diversos tipos de indústrias cujo processo produtivo apresenta pintura em superfícies metálicas, especificamente na etapa denominada fosfatização. Este trabalho apresenta uma forma de reaproveitamento da borra de fosfato, através de sua utilização como matéria-prima alternativa para a fabricação de blocos cerâmicos (tijolos), visando reduzir os custos e prejuízos ambientais relativos à disposição final deste resíduo; além de reduzir os impactos ambientais decorrentes da extração de matérias-primas diretamente do meio ambiente. Os resultados obtidos neste trabalho permitem concluir que para as diferentes formulações testadas, a quantidade de $10 \%$ de borra de fosfato usada na substituição da argila para a fabricação dos tijolos é a ideal, recomendando o seu uso como bloco de vedação classe 10 .

PALAVRAS-CHAVE: Resíduos sólidos industriais; borra de fosfato; reutilização; blocos cerâmicos; tijolos.

\begin{abstract}
The "Phosphate Sludge Waste" is generated by various types of industries whose manufacturing process entails phosphatizing treatment during coating on metallic surfaces. The present study presents an option for recycling Phosphate Sludge Waste as an alternative raw material in the manufacturing of ceramic blocks (bricks), in order to lower the costs and environmental damages arising from the disposal of such residue, and yet sparing environmental impacts due to the extraction of natural resources. The results demonstrated in this work has shown that the best formulation mix was the one that used 10\% of phosphate waste in substitution to clay, recommended its use as class 10 ceramic blocks.
\end{abstract}

KEYWORDS: Industrial solid waste; phosphate sludge; reutilization; ceramic blocks; bricks.

\section{INTRODUÇÃO}

Os resíduos provenientes das atividades industriais crescem em importância no cenário ambiental, uma vez que são gerados por vários tipos de processos, representando uma produção de milhões de toneladas por dia em todo o mundo. A antiga visão de que a questão ambiental se concentrava nos recursos hídricos e atmosféricos foi ampliada quando a disposição adequada de resíduos passou a ser primordial para a preservação ambiental. Daí a necessidade de se desenvolverem mecanismos para promover a conscientização e a busca de soluçóes para a implantação de tecnologias capazes de, a um só tempo, minimizar os impactos decorrentes da disposição destes resíduos no meio ambiente e reduzir os custos envolvidos nesta atividade.

Nesta visão, a reciclagem de resíduos é fundamental para uma sociedade apoiada no desenvolvimento sustentável (ENBRI, 1994), capaz de satisfazer as necessidades do conjunto da população do presente, sem comprometer a capacidade de sobrevivência das gerações futuras. Desta forma, o desenvolvimento de estudos visando a reciclagem (ou reutilização) dos resíduos representa uma alternativa capaz de contribuir para a utilização de matérias-primas alternativas, diminuindo os custos finais dos setores industriais geradores e consumidores dos resíduos, além de preservar o meio ambiente.

O resíduo conhecido como "borra de fosfato" é gerado em indústrias que possuem em seu processo produtivo a etapa de pintura em superfícies metálicas (montadoras, fabricantes de autopeças, máquinas diversas, móveis, eletrodomésticos, etc). Este resíduo é, na maioria das vezes disposto inadequadamente em aterros sanitários e/ou lixões. Em alguns casos, é encaminhado para aterros industriais, ou tratado através de processos como o de resina de troca iônica (Nishino, 1994).

Quanto a sua geração, tem-se o exemplo no Estado de Minas Gerais. A Secretaria de Estado de Meio Ambiente e Desenvolvimento Sustentável, realizou o Inventário Estadual de Resíduos Sólidos Industriais através da Fundação Estadual do Meio Ambiente - FEAM. Este inventário faz parte da estratégia nacional 
para a gestão de resíduos sólidos industriais, estabelecida através da Resolução CONAMA no 313 de 29 de outubro de 2002. A Tabela 1 apresenta os ramos industriais que apontaram a geração do resíduo borra de fosfato em seu processo produtivo, de acordo com o Inventário.

Tendo em vista que a geração do resíduo borra de fosfato está relacionada diretamente com a atividade de pintura, pesquisou-se também a possibilidade dele ter sido incorporado por algumas empresas quando do preenchimento do inventário, como "resíduos e lodos de tinta da pintura industrial" ou "lodos de sistema de tratamento de águas residuárias da pintura industrial", e por isso a geração efetiva do resíduo borra de fosfato no Estado de Minas Gerais possa ser maior do que a indicada na Tabela 1 . Assim, a Tabela 2 apresenta a quantidade gerada e o destino dos resíduos apontados no Inventário nos quais possa estar contido, em parte, $\mathrm{o}$ resíduo borra de fosfato.

Algumas aplicações para a borra de fosfato têm sido estudadas, como a fabricação de fertilizantes ou para a composição de asfalto e agregados da construção civil. A construção civil é um ramo da atividade tecnológica que, pelo volume de recursos naturais consumidos, pode ser largamente indicado para absorver resíduos sólidos. Segundo John (1999), a construção civil é o setor responsável pelo consumo de maior volume de recursos naturais, em estimativas que variam entre $15 e$ $50 \%$ dos recursos extraidos, além de seus produtos serem grandes consumidores de energia, e por estas razóes, é de fundamental importancia o desenvolvimento de materiais alternativos que atendam a construção civil.

O comportamento da borra adicionada como matéria-prima no processo de produção do clínquer de cimento Portland com vista ao co-processamento deste resíduo e a avaliação do clínquer produzido do ponto de vista da sua interação com o meio ambiente foi estudado por Caponero (1999). Os resultados desta pesquisa mostraram não haver comprometimento do processo de clinquerização para adições de até $7 \%$ do resíduo à farinha (matéria-prima convencional), tendo sido observado basicamente o aumento do teor de zinco na mesma. A avaliação da toxicidade mostrou, ainda, que o clínquer produzido utilizandose borra de fosfato não apresenta riscos ao meio ambiente.

Contudo, como já exposto, a importância de incentivar a reciclagem des-

Tabela I - Ramos industriais que geram o resíduo borra de fosfato em Minas Gerais

\begin{tabular}{|c|c|c|}
\hline Ramo industrial & Geração (t/ano) & Destino \\
\hline \multirow{4}{*}{$\begin{array}{c}\text { Fabricação de produtos de metal } \\
\text { (exclusive máquinas e } \\
\text { equipamentos) }\end{array}$} & 0,30 & Sem destino definido \\
\hline & 0,72 & Sem destino definido \\
\hline & 14,50 & Sem destino definido \\
\hline & 60,00 & Aterro industrial de terceiros \\
\hline $\begin{array}{l}\text { Fabricação de máquinas e } \\
\text { equipamentos }\end{array}$ & 36,00 & Aterro sanitário municipal \\
\hline \multirow{2}{*}{$\begin{array}{l}\text { Fabricação de máquinas, } \\
\text { aparelhos e materiais elétricos }\end{array}$} & 14,40 & Sem destino definido \\
\hline & 0,50 & Sem destino definido \\
\hline \multirow{4}{*}{$\begin{array}{c}\text { Fabricação e montagem de } \\
\text { veículos automotores, reboques } \\
\text { e carrocerias }\end{array}$} & 14,16 & Sem destino definido \\
\hline & 2,50 & $\begin{array}{l}\text { Co-processamento em fornos de } \\
\text { cimento }\end{array}$ \\
\hline & 10,60 & Incineração \\
\hline & 7,20 & Sem destino definido \\
\hline $\begin{array}{l}\text { Fabricação de produtos } \\
\text { químicos }\end{array}$ & 16,03 & $\begin{array}{l}\text { Co-processamento em fornos de } \\
\text { cimento }\end{array}$ \\
\hline \multirow[t]{2}{*}{ Metalurgia Básica } & 40,80 & Incorporação em solo agrícola \\
\hline & 525,00 & $\begin{array}{c}\text { Reutilização externa (indústria de } \\
\text { pigmentos) }\end{array}$ \\
\hline Total & & $742,71 \mathrm{t} /$ ano \\
\hline
\end{tabular}

Fonte: FEAM, 2003.

te tipo de resíduo, por exemplo em setores cerâmicos, que englobam em grande parte a construção civil, pode contribuir para diversificar a oferta de matérias-primas para produção de componentes cerâmicos e reduzir os custos da construção civil, o que é de vital importância, principalmente em um país com elevado déficit habitacional como o Brasil. Dentre os produtos fabricados pela indústria cerâmica vermelha, destacam-se os blocos cerâmicos (tijolos), telhas, lajotas para piso e forro e tubos cerâmicos. Diversos estudos para o reaproveitamento de resíduos industriais na indústria cerâmica, sobretudo para a fabricação de tijolos, já foram realizados com sucesso, podendose citar a utilização de lamas de Estações de Tratamento de Efluentes, cinzas de usinas hidrelétricas, areias de fundição, refugos de mineração, escórias de fornos, resíduos de serragem de granito, entre outros (USEPA, 2003).

Neste sentido, este trabalho se justifica como uma busca de tecnologias apropriadas e mais limpas, capazes de promover o reaproveitamento do resíduo borra de fosfato na fabricação de blocos cerâmicos (tijolos), com o intuito de:

- Reduzir custos e prejuízos ambientais relativos ao tratamento e/ou disposição final deste resíduo;

- Reduzir impactos ambientais decorrentes da extração de matérias-primas diretamente do meio ambiente.

\section{METODOLOGIA}

\section{Identificação do processo gerador do resíduo}

A identificação do processo de geração do resíduo borra de fosfato foi realizada na montadora FIATAUTOMÓVEIS, localizada no município de Betim/MG, tendo em vista que este tipo de indústria se configura como um grande gerador do resíduo em estudo. Para tal, foram realizadas diversas visitas em campo, além de levantamentos de dados e informações acerca do processo produtivo através de documentos técnicos e junto aos funcionários da empresa. 
Tabela 2 - Outros tipos de resíduos nos quais pode estar contida a borra de fosfato

\begin{tabular}{|c|c|c|c|}
\hline Ramo industrial & Nome do resíduo & Geração (t/ano) & Destino \\
\hline \multirow[t]{2}{*}{$\begin{array}{c}\text { Fabricação de máquinas e } \\
\text { equipamentos }\end{array}$} & $\begin{array}{l}\text { Resíduos e lodos de tinta da } \\
\text { pintura industrial }\end{array}$ & 65,60 & $\begin{array}{l}\text { Sem destino definido, co- } \\
\text { processamento em fornos de } \\
\text { cimento e sucateiros } \\
\text { intermediários }\end{array}$ \\
\hline & $\begin{array}{c}\text { Lodos de sistema de tratamento } \\
\text { de águas residuárias da pintura } \\
\text { industrial }\end{array}$ & 27,10 & Sem destino definido \\
\hline \multirow[t]{2}{*}{$\begin{array}{l}\text { Fabricação de máquinas, } \\
\text { aparelhos e materiais elétricos }\end{array}$} & $\begin{array}{l}\text { Resíduos e lodos de tinta da } \\
\text { pintura industrial }\end{array}$ & 0,99 & $\begin{array}{l}\text { Sem destino definido e co- } \\
\text { processamento em fornos de } \\
\text { cimento }\end{array}$ \\
\hline & $\begin{array}{c}\text { Lodos de sistema de tratamento } \\
\text { de águas residuárias da pintura } \\
\text { industrial }\end{array}$ & 37,30 & $\begin{array}{l}\text { Co-processamento em fornos de } \\
\text { cimento }\end{array}$ \\
\hline \multirow[t]{2}{*}{$\begin{array}{l}\text { Fabricação de produtos } \\
\text { químicos }\end{array}$} & $\begin{array}{c}\text { Resíduos e lodos de tinta da } \\
\text { pintura industrial }\end{array}$ & 34,20 & $\begin{array}{l}\text { Co-processamento em fornos de } \\
\text { cimento }\end{array}$ \\
\hline & $\begin{array}{c}\text { Lodos de sistema de tratamento } \\
\text { de águas residuárias da pintura } \\
\text { industrial }\end{array}$ & 43,90 & $\begin{array}{l}\text { Co-processamento em fornos de } \\
\text { cimento }\end{array}$ \\
\hline \multirow[t]{2}{*}{$\begin{array}{c}\text { Fabricação de produtos de metal } \\
\text { (exclusive máquinas e } \\
\text { equipamentos) }\end{array}$} & $\begin{array}{l}\text { Resíduos e lodos de tinta da } \\
\text { pintura industrial }\end{array}$ & 182,50 & $\begin{array}{c}\text { Sem destino definido, Aterro } \\
\text { sanitário municipal e sucateiros } \\
\text { intermediários }\end{array}$ \\
\hline & $\begin{array}{c}\text { Lodos de sistema de tratamento } \\
\text { de águas residuárias da pintura } \\
\text { industrial }\end{array}$ & - & - \\
\hline \multirow[t]{2}{*}{$\begin{array}{c}\text { Fabricação e montagem de } \\
\text { veículos automotores, reboques } \\
\text { e carrocerias }\end{array}$} & $\begin{array}{l}\text { Resíduos e lodos de tinta da } \\
\text { pintura industrial }\end{array}$ & 289,44 & $\begin{array}{l}\text { Sem destino definido e co- } \\
\text { processamento em fornos de } \\
\text { cimento }\end{array}$ \\
\hline & $\begin{array}{c}\text { Lodos de sistema de tratamento } \\
\text { de águas residuárias da pintura } \\
\text { industrial }\end{array}$ & 2436,50 & $\begin{array}{l}\text { Sem destino definido, co- } \\
\text { processamento em fornos de } \\
\text { cimento e aterro industrial de } \\
\text { terceiros }\end{array}$ \\
\hline \multirow[t]{3}{*}{ Metalurgia básica } & $\begin{array}{l}\text { Resíduos e lodos de tinta da } \\
\text { pintura industrial }\end{array}$ & 20,00 & Incineração \\
\hline & $\begin{array}{c}\text { Lodos de sistema de tratamento } \\
\text { de águas residuárias da pintura } \\
\text { industrial }\end{array}$ & - & - \\
\hline & Total & & 3137,53 t/ano \\
\hline
\end{tabular}

Fonte: FEAM, 2003.

\section{Caracterização e classificação da borra de fosfato}

\section{1) Amostragem}

A amostragem do resíduo borra de fosfato gerado no processo produtivo da FIAT foi realizada conforme orientaçóes da norma NBR 10007/04 da ABNT.

\section{2) Escolha de parâmetros}

A escolha dos parâmetros descritos na Tabela 3, para a caracterização e classi- ficação da borra de fosfato foi feita após a avaliação de seu processo de geração, uma vez que a composição química qualitativa de resíduos está relacionada aos componentes das matérias-primas utilizadas no processo produtivo responsável pela sua geração, bem como às reaçôes que ocorrem durante este processo.

O ensaio para a caracterização do resíduo permite avaliar as concentraçōes dos parâmetros escolhidos. Os ensaios de lixiviação e solubilização permitem a classificação do resíduo conforme determi- nações da norma NBR 10004/04 da ABNT (Classes I e II - A e B), através da comparação dos resultados obtidos nas análises e os valores máximos de concentraçōes definidos nas tabelas dos Anexos $F$ (para o ensaio de lixiviação), G (para o ensaio de solubilização) desta mesma norma. Os ensaios de lixiviação e solubilização foram realizados conforme descrito nas normas NBR 10005/04 e 10006/04, respectivamente. 
Tabela 3 - Parâmetros selecionados para a caracterização e classificação da borra de fosfato

\begin{tabular}{cc}
\hline Ensaio & Parâmetros \\
\hline Caracterização & $\begin{array}{c}\text { Fosfato, Alumínio, Cádmio, Chumbo, } \\
\text { Cobre, Cromo, Manganês, Zinco, } \\
\text { Sódio, Níquel e Ferro }\end{array}$ \\
Lixiviação & Fluoretos, Cádmio, Chumbo e Cromo \\
Solubilização & Fluoretos, Alumínio, Cádmio, \\
& $\begin{array}{c}\text { Chumbo, Cobre, Cromo, Manganês, } \\
\text { Zinco, Sódio, Ferro e Dureza }\end{array}$ \\
\hline
\end{tabular}

\section{Formulação da mistura borra $x$ argila - análise em laboratório}

Esta etapa do trabalho consistiu na análise, em laboratório, do percentual mais indicado para incorporação da borra de fosfato na massa cerâmica para a fabricação de tijolos, em substituição da argila. Para tal, foram confeccionados e analisados corpos de prova, conforme descrito a seguir.

\section{Prova}

\section{1) Confecção dos Corpos de}

Para a confecção dos corpos de prova foram utilizados dois tipos de matérias-primas: a argila (matéria-prima convencional) e a borra de fosfato (matéria-prima alternativa), visando identificar qual percentual de mistura entre elas era o mais indicado para a fabricação de tijolos. A amostra de borra de fosfato foi coletada na FIAT e a amostra de argila foi coletada de uma pilha da fábrica de tijolos denominada CERÂMICA VILAÇA, localizada no município de Pitangui/MG, proveniente de uma jazida de argila localizada no município de Conceição do Pará/MG.

Foram moldados, em triplicata, corpos de prova contendo as seguintes proporções do resíduo: $0 \%, 5 \%, 10 \%$ e $20 \%$, tendo sido utilizados os seguintes materiais e equipamentos: balança analítica digital, soquete de aço, peneira com diâmetro de malha de 2,0 mm, espátula de aço, béquer, bandejas de alumínio, moldes de aço (cilindro vazado, com altura de $9,1 \mathrm{~cm}$ e diâmetros interno e externo de $5,0 \mathrm{~cm}$ e $7,6 \mathrm{~cm}$, respectivamente), êmbolo de aço (altura de 19,5 cm e diâmetro de $5,0 \mathrm{~cm}$ ), estufa com controle de temperatura de até $200^{\circ} \mathrm{C}$ e mufla com controle de temperatura de até $1200^{\circ} \mathrm{C}$.

Os corpos de prova moldados foram mantidos à temperatura ambiente por 24 horas e levados à estufa para seca- gem final, à temperatura de $105^{\circ} \mathrm{C}$, por mais 24 horas. Em seguida, procedeu-se à operação de queima na mufla, aumentando-se gradualmente a sua temperatura até $850^{\circ} \mathrm{C}$, a fim de seguir o mais fielmente possível os procedimentos que ocorrem em escala industrial (de acordo com o perfil térmico do forno da fábrica de tijolos onde posteriormente foi realizado o teste de queima).

Após a queima, os corpos de prova foram submetidos a testes físicos para verificação da resistência à compressão, tendo sido os destroços deste ensaio encaminhados para análises físico-químicas a fim de verificar a classificação dos mesmos segundo a norma NBR 10004/04. É importante destacar que os corpos de prova contendo $20 \%$ de resíduo não foram classificados, em função dos resultados obtidos no ensaio de resistência à compressão.

O critério para a escolha dos parâmetros foi o mesmo utilizado para a classificação do resíduo puro. A tabela 4 apresenta os parâmetros selecionados para cada ensaio.

\section{Análise, em escala industrial, da viabilidade da incorporação da borra de fosfato para a fabricação de tijolos (teste de queima)}

$\mathrm{O}$ teste de queima foi realizado na CERÂMICA VILAÇA, apenas para o percentual mais indicado pelos testes de laboratório para a fabricação de tijolos, ou seja, $10 \%$, seguindo todas as etapas de processo realizadas normalmente nesta fábrica, a saber: entrada das matériasprimas, desintegração e mistura, laminação, extrusão, corte (196 tijolos de $(15 \times 20 \times 30) \mathrm{cm}$ e 12 furos, secagem e queima.

Os tijolos com e sem borra de fosfato fabricados durante o teste de queima foram submetidos a testes físicos para verificação da resistência à compressão e absorção de água. Os tijolos contendo 10\% do resíduo foram ainda submetidos a análises físico-químicas para verificação de sua classificação conforme a NBR 10004/04, cujos parâmetros escolhidos foram os mesmos analisados para os corpos de prova.

\section{RESULTADOS}

\section{Identificação do processo gerador do resíduo}

Na fábrica da FIAT AUTOMÓVEIS, as carrocerias, após a saída da Funilaria, seguem para a Unidade Operativa de Pintura. Esta é composta por uma etapa de pré-tratamento, que visa preparar a carroceria dos veículos para o recebimento da pintura propriamente dita, através de eletrodeposição catódica.

O resíduo borra de fosfato é gerado na etapa de pré-tratamento da pintura, especificamente durante a fosfatização. A fosfatização é um processo de proteção de metais que consiste em recobrir peças metálicas com fosfatos neutros $\mathrm{PO}_{4}^{-3}$ e monoácidos $\left[\mathrm{H}\left(\mathrm{PO}_{4}\right)_{2}\right]=$ de zinco, manganês e ferro. Como os fosfatos desses elementos são pouco solúveis em água, depositam-se sobre a superfície metálica, sob a forma de uma fina camada de cristais. A fosfatização tem como objetivo evitar a corrosão e melhorar a aderência, a resistência e a vida útil da pintura.

No caso da FIAT, a fosfatização consiste na imersão da carroceria do veículo em um tanque contendo uma mistura ácida composta por ácido fosfórico (5-10\%), fosfato de zinco (10-15\%), 
fosfato de manganês (5-10\%), nitrato de níquel $(0,1-5 \%)$, nitrato de zinco $(0,1-5 \%)$, fluoreto de potássio $(0,1-2 \%)$ e água. $A$ acidez livre da mistura ataca a superfície metálica, havendo liberação de íons $\mathrm{Fe}^{+2}$ no meio líquido. A adição de nitrito de sódio $\left(\mathrm{NaNO}_{2}\right)$ no tanque de fosfatização faz com que o ferro precipite na forma $\mathrm{Fe}^{+3}$, dando origem a um material sólido que se deposita no fundo do tanque, em cones conhecidos como "tetas". Das "tetas", o material pastoso contendo os sólidos é bombeado para dois decantadores (primário e secundário) e em seguida para um filtro-prensa, para que seja feita a redução do teor de umidade existente no material. $O$ líquido retido no filtro é recirculado para o tanque de fosfatização e a parte sólida, a borra de fosfato, depositada em caçamba enquanto aguarda sua destinação final. É importante destacar que o resíduo é gerado de forma bastante homogênea.

Atualmente, são geradas na FIAT cerca de 11 toneladas mensais de borra de fosfato, que são destinadas ao coprocessamento em forno de clínquer. A Figura 1 apresenta o fluxograma da geração da borra de fosfato.

\section{Caracterização e classificação da borra de fosfato}

As Tabelas 5, 6 e 7 apresentam, respectivamente, os resultados obtidos nos ensaios de caracterização, lixiviação e solubilização do resíduo borra de fosfato.

Os resultados demonstram que os principais constituintes da borra são ferro, zinco, níquel e sódio em função do ataque na superfície metálica das carrocerias e da constituição da mistura ácida do tanque de fosfatização. Os resultados obtidos nos três ensaios classificam o resíduo como Classe II - A (não perigoso e não inerte), tendo em vista que o extrato solubilizado apresentou resultados acima do limite estabelecido pelo anexo G da NBR 10004/04 para os parâmetros alumínio, manganês, zinco e sódio. $\mathrm{O}$ ensaio de lixiviação não apresentou nenhum resultado acima dos limites estabelecidos no anexo $\mathrm{F}$, descartando, portanto a classificação do resíduo como perigoso (Classe I).

\section{Formulação da mistura borra $x$ argila - análise em laboratório}

Os corpos de prova, moldados em triplicata com as massas contendo

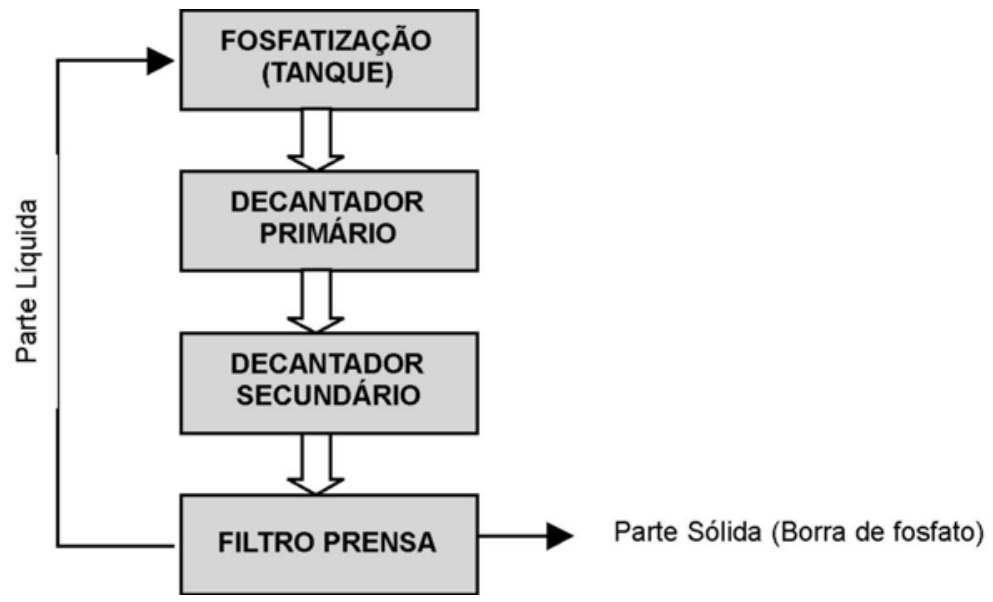

Figura I - Fluxograma da geração da borra de fosfato

Tabela 5 - Resultados do ensaio de caracterização do resíduo borra de fosfato

\begin{tabular}{cc}
\hline Parâmetros & Resultados \\
\hline Fosfato (como fósforo) & $<1,0 \mathrm{mg} / \mathrm{Kg}$ \\
Alumínio & $185,0 \mathrm{mg} / \mathrm{Kg}$ \\
Cádmio & $49,0 \mathrm{mg} / \mathrm{Kg}$ \\
Chumbo & $<1,0 \mathrm{mg} / \mathrm{Kg}$ \\
Cobre & $<0,6 \mathrm{mg} / \mathrm{Kg}$ \\
Cromo total & $99,0 \mathrm{mg} / \mathrm{Kg}$ \\
Manganês & $1,8 \%$ \\
Zinco & $7,9 \%$ \\
Sódio & $3,3 \%$ \\
Níquel & $2110,0 \mathrm{mg} / \mathrm{Kg}$ \\
Ferro & $15,0 \%$ \\
\hline
\end{tabular}

Tabela 6 - Resultados do ensaio de lixiviação do resíduo borra de fosfato

\begin{tabular}{ccc}
\hline Parâmetros & Resultados $(\mathrm{mg} / \mathrm{L})$ & Limites $(\mathrm{mg} / \mathrm{L})^{*}$ \\
\hline Fluoretos & 2,0 & 150,0 \\
Cádmio & $<0,002$ & 0,5 \\
Chumbo & $<0,02$ & 1,0 \\
Cromo total & $<0,006$ & 5,0 \\
*Anexo F da Norma NBR & $10004 / 04$
\end{tabular}


$0 \%, 5 \%, 10 \%$ e $20 \%$ do resíduo borra de fosfato e o restante de argila, foram submetidos a testes físicos para verificação da resistência à compressão, cujos resultados obtidos são apresentados na Tabela 8 .

Os resultados indicam que os corpos de prova contendo $0 \%, 5 \%$ e $10 \%$ do resíduo borra de fosfato apresentaram resultados bastante semelhantes, enquanto que a resistência à compressão dos corpos de prova contendo $20 \%$ de borra foi inferior. Visualmente, este resultado pode ser explicado em função de um aumento da porosidade dos corpos de prova contendo $20 \%$ de borra, quando rompidos durante o ensaio.

Desta forma, este ensaio possibilitou que fosse descartada a possibilidade de incorporação do percentual de $20 \%$ de borra de fosfato na massa cerâmica. Os destroços dos corpos de prova contendo $0 \%, 5 \%$ e $10 \%$ de borra de fosfato foram encaminhados para as análises físico-químicas, através de ensaios de solubilização e lixiviação, com intuito de serem classificados segundo a norma NBR 10004/04 da ABNT. As Tabelas 9 e 10 apresentam os resultados obtidos.

De uma forma geral, pode-se dizer que os resultados obtidos para as três formulaçôes foram similares, podendo-se observar um pequeno aumento da concentração de sódio e uma pequena redução das concentraçôes de cromo e ferro no extrato solubilizado, quando se aumenta o teor do resíduo. Estas alterações podem ser explicadas em função da própria composição do resíduo (o teor de sódio no extrato solubilizado da borra de fosfato apresentou-se elevado), ou ainda pela variação da solubilidade destes elementos na presença apenas de silicatos (constituintes da argila) e na presença de fosfato (constituinte do resíduo).

O ensaio de lixiviação não apresentou nenhum resultado acima do limite estabelecido no anexo $\mathrm{F}$, descartando portanto a classificação dos corpos de prova como resíduos perigosos.

Tendo em vista que o alumínio apresentou, para todos os extratos solubilizados, uma concentração acima do limite estabelecido no anexo $G$ da NBR 10004/04, todos os corpos de prova foram classificados como Classe II-A (Não perigoso - não inerte), incluindo os corpos de prova contendo $0 \%$ de resíduo (ou seja, $100 \%$ de argila). Por este motivo, optou-se por realizar o teste de queima com uma formulação, em massa, de $10 \%$ de resíduo para $90 \%$ de argila.

Tabela 7 - Resultados do ensaio de solubilização do resíduo borra de fosfato

\begin{tabular}{ccc}
\hline Parâmetros & Resultados $(\mathrm{mg} / \mathrm{L})$ & ${\text { Limites }(\mathrm{mg} / \mathrm{L})^{*}}^{*}$ \\
\hline Fluoretos & 0,30 & 1,5 \\
Alumínio & 0,6 & 0,2 \\
Cádmio & $<0,002$ & 0,005 \\
Chumbo & $<0,01$ & 0,01 \\
Cobre & $<0,003$ & 2,0 \\
Cromo total & $<0,006$ & 0,05 \\
Manganês & 146,0 & 0,1 \\
Zinco & 224,0 & 5,0 \\
Sódio & 807,0 & 200,0 \\
Ferro & 0,3 & 0,3 \\
\hline
\end{tabular}

*Anexo G da Norma NBR 10004/04

Tabela 8 - Resultados do ensaio de resistência à compressão dos corpos de prova

\begin{tabular}{ccccc}
\hline $\begin{array}{c}\text { Percentual de } \\
\text { resíduo }\end{array}$ & \multicolumn{4}{c}{ Resistência à compressão $\left(\mathrm{Kgf} / \mathrm{cm}^{2}\right)$} \\
Corpo de & $\begin{array}{c}\text { Corpo de } \\
\text { prova 1 } 2\end{array}$ & $\begin{array}{c}\text { Corpo de } \\
\text { prova 3 }\end{array}$ & Média \\
\hline $0 \%$ & 78,2 & 82,6 & 65,7 & 75,5 \\
$5 \%$ & 67,6 & 68,8 & 81,3 & 72,6 \\
$10 \%$ & 78,2 & 72,6 & 73,8 & 74,9 \\
$20 \%$ & 41,3 & 25,7 & 25,0 & 30,7 \\
\hline
\end{tabular}

Tabela 9 - Resultados do ensaio de lixiviação dos corpos de prova

\begin{tabular}{|c|c|c|c|c|}
\hline \multirow[t]{2}{*}{ Parâmetros } & \multicolumn{3}{|c|}{ Resultados (mg/L) } & \multirow{2}{*}{$\begin{array}{l}\text { Limites } \\
(\mathrm{mg} / \mathrm{L})^{*}\end{array}$} \\
\hline & $0 \%$ & $5 \%$ & $10 \%$ & \\
\hline Fluoretos & $<0,2$ & $<0,2$ & $<0,2$ & 150,0 \\
\hline Cádmio & $<0,02$ & $<0,02$ & $<0,02$ & 0,5 \\
\hline Chumbo & $<0,20$ & $<0,20$ & $<0,20$ & 1,0 \\
\hline Cromo total & $<0,05$ & $<0,05$ & $<0,05$ & 5,0 \\
\hline
\end{tabular}

*Anexo F da Norma NBR 10004/04

\section{Análise, em escala industrial, da viabilidade da incorporação da borra de fosfato para a fabricação de tijolos}

Os tijolos contendo e não contendo borra de fosfato, fabricados durante o teste de queima foram submetidos aos ensaios físicos para verificação da resistência à compressão e da absorção de água. A umidade do resíduo borra de fosfato e da argila encontrava-se na faixa de 20-25\% umidade. Os resultados são apresentados nas Tabelas 11 e 12 .

Pela tabela 11, observa-se que os resultados da resistência à compressão dos tijolos contendo e não contendo o resíduo borra de fosfato foram bastante semelhantes. Nos dois casos houve pouca dispersão dos resultados, não havendo necessidade de se fazer um tratamento 
Tabela 10 - Resultados do ensaio de solubilização dos corpos de prova

\begin{tabular}{cccccccc}
\hline Parâmetros & \multicolumn{3}{c}{ Resultados $(\mathrm{mg} / \mathrm{L})$} & \multicolumn{3}{c}{ Resultados $(\mathrm{mg} / \mathrm{L})^{*}$} & Limites \\
& $0 \%$ & $5 \%$ & $10 \%$ & $0 \%$ & $5 \%$ & $10 \%$ & $(\mathrm{mg} / \mathrm{L})^{* *}$ \\
\hline Fluoretos & 0,2 & 0,6 & 0,7 & $<0,2$ & 0,6 & 0,8 & 1,5 \\
Alumínio & 1,331 & 1,375 & 1,404 & 1,450 & 1,436 & 1,196 & 0,2 \\
Cádmio & $<0,005$ & $<0,005$ & $<0,005$ & $<0,005$ & $<0,005$ & $<0,005$ & 0,005 \\
Chumbo & $<0,001$ & $<0,001$ & $<0,001$ & $<0,001$ & $<0,001$ & $<0,001$ & 0,01 \\
Cobre & $<0,05$ & $<0,05$ & $<0,05$ & $<0,05$ & $<0,05$ & $<0,05$ & 2,0 \\
Cromo & 0,0354 & 0,0184 & 0,0111 & 0,0556 & 0,0186 & 0,0190 & 0,05 \\
Manganês & $<0,05$ & $<0,05$ & $<0,05$ & $<0,05$ & $<0,05$ & $<0,05$ & 0,1 \\
Zinco & 0,0313 & 0,0617 & 0,1053 & 0,0613 & 0,0775 & 0,0753 & 5,0 \\
Sódio & 0,4580 & 2,314 & 4,359 & 0,5207 & 2,418 & 4,483 & 200,0 \\
Ferro & 0,26 & $<0,05$ & $<0,05$ & 0,20 & 0,11 & $<0,05$ & 0,3 \\
\hline
\end{tabular}

*Análise em duplicata

**Anexo G da Norma NBR 10004/04

Tabela I I - Resultados do ensaio de resistência à compressão dos tijolos

\begin{tabular}{cccccccccccc}
\hline $\begin{array}{c}\text { Percentual de } \\
\text { resíduo }\end{array}$ & 1 & 2 & 3 & 4 & 5 & 6 & 7 & 8 & 9 & 10 & Média \\
\hline $0 \%$ & 12,1 & 9,9 & 10,3 & 9,4 & 8,6 & 12,8 & 11,1 & 10,3 & 8,9 & 11,8 & 10,5 \\
$10 \%$ & 9,9 & 11,8 & 8,9 & 9,1 & 10,3 & 8,9 & 10,1 & 11,3 & 9,9 & 9,4 & 10,0 \\
\hline
\end{tabular}

estatístico. De acordo com a norma NBR $7171 / 92$, os tijolos com $0 \%$ e $10 \%$ de resíduo são classificados como bloco de vedação classe 10 , por terem apresentado resistência à compressão entre $10 \mathrm{Kgf} / \mathrm{cm}^{2}(1 \mathrm{MPa})$ e $15 \mathrm{Kgf} / \mathrm{cm}^{2}$ (1,5 MPa). Desta forma, pode-se dizer que o tijolo contendo o resíduo borra de fosfato, embora tenha apresentado uma resistência à compressão ligeiramente inferior, é comercialmente equivalente ao tijolo que não contém este resíduo.

Os resultados obtidos indicam que o tijolo fabricado com o resíduo borra de fosfato atende à norma NBR 7171/92 que estabelece, para blocos cerâmicos, a absorção de água não inferior a $8 \%$ nem superior a $25 \%$. Observa-se, ainda, que os resultados da absorção de água para os tijolos com $0 \%$ de resíduo foram bastante semelhantes àqueles com $10 \%$ de resíduo.

Após os ensaios físicos, uma amostra dos destroços dos tijolos contendo $10 \%$ de borra de fosfato foram encaminhados para as análises físico-químicas através de ensaios de solubilização e lixiviação, com intuito de classificá-la se-

Tabela 12 - Resultados do ensaio de absorção de água

\begin{tabular}{ccccc}
\hline \multirow{2}{*}{$\begin{array}{c}\text { Percentual de } \\
\text { resíduo }\end{array}$} & Tijolo 1 & Tijolo 2 & Tijolo 3 & Média \\
\hline $0 \%$ & 22,2 & 23,1 & 22,5 & 22,6 \\
$10 \%$ & 21,2 & 21,0 & 20,6 & 20,9 \\
\hline
\end{tabular}

gundo a norma NBR 10004/04 da ABNT. As Tabelas 13 e14 apresentam os resultados obtidos.

O ensaio de lixiviação não apresentou nenhum resultado acima do limite estabelecido no anexo F, descartando portanto a classificação do tijolo como um resíduo perigoso. Para o extrato solubilizado, observa-se uma concentração acima do limite estabelecido no anexo $\mathrm{G}$ da NBR 10004/04 para os parâmetros alumínio, ferro, manganês e cromo, e por isso, o tijolo contendo $10 \%$ do resíduo borra de fosfato é classificado como Classe II-A (Não perigoso - não inerte).

No entanto, assim como para os resultados obtidos nas análises físico-químicas dos corpos de prova, a presença do alumínio era esperada, tendo em vista a composição da argila. Analogamente, ainda que em menor quantidade, o ferro e o manganês estão presentes na constituição da argila, sendo o manganês geoquimicamente semelhante ao ferro, ou seja, a presença do manganês se encontra associada à do ferro.

Quando da caracterização e classificação da borra de fosfato, observou-se uma alta concentração de ferro, porém, no ensaio de solubilização, este parâmetro não extrapolou o limite estabelecido pelo anexo G da NBR 10004/04. Em relação ao manganês, observou-se o contrário, pois a concentração deste elemento durante a caracterização foi baixa, mas no extrato solubilizado o valor encontrado foi acima 
Tabela I 3 - Resultados do ensaio de lixiviação do tijolo contendo 10\% de borra

\begin{tabular}{ccc}
\hline Parâmetros & Resultados $(\mathrm{mg} / \mathrm{L})$ & Limites $(\mathrm{mg} / \mathrm{L})^{*}$ \\
\hline Fluoretos & 0,28 & 150,0 \\
Cádmio & $<0,002$ & 0,5 \\
Chumbo & $<0,021$ & 1,0 \\
Cromo total & $<0,2$ & 5,0 \\
\hline
\end{tabular}

*Anexo F da Norma NBR 10004/04

Tabela 14 - Resultados do ensaio de solubilização do tijolo contendo 10\% de borra

\begin{tabular}{ccc}
\hline Parâmetros & Resultados $(\mathrm{mg} / \mathrm{L})$ & Limites $(\mathrm{mg} / \mathrm{L})^{*}$ \\
\hline Fluoretos & 0,06 & 1,5 \\
Alumínio & 1,3 & 0,2 \\
Cádmio & $<0,002$ & 0,005 \\
Chumbo & $<0,01$ & 0,01 \\
Cobre & $<0,003$ & 1,0 \\
Cromo Total & 0,6 & 0,05 \\
Manganês & 2,3 & 0,1 \\
Zinco & 1,0 & 5,0 \\
Sódio & 2,5 & 200,0 \\
Ferro & 0,4 & 0,3 \\
\hline
\end{tabular}

*Anexo G da Norma NBR 10004/04

do limite. Vale ainda lembrar que, nas análises dos corpos de prova, a concentração de ferro no extrato solubilizado contendo $0 \%$ de resíduo foi maior que a encontrada no extrato contendo $10 \%$ de resíduo. Para o manganês, as concentraçôes foram iguais para estes dois percentuais, ou seja, abaixo do limite de detecção do equipamento.

Em relação ao cromo, sua presença foi observada tanto na argila quanto na massa bruta do resíduo borra de fosfato, embora a concentração deste elemento no ensaio de solubilização do resíduo não tenha extrapolado o limite estabelecido pelo anexo G da NBR 10004/04. Assim como para o parâmetro ferro, a concentração de cromo no extrato solubilizado do corpo de prova contendo $0 \%$ de resíduo foi maior que a encontrada no extrato do corpo de prova contendo $10 \%$ de resíduo.

Os resultados obtidos para o ferro e para o cromo no ensaio de solubilização dos corpos de prova indicam ser possível que a concentração destes parâmetros em um tijolo contendo apenas argila $(0 \%$ de resíduo) possa ser maior que no tijolo contendo $10 \%$ do resíduo. Isto porque o fosfato presente no resíduo tem mais poder de "fixação" destes metais do que o silicato presente na argila, ou seja, o grau de solubilidade na presença apenas da argila poderia ser maior, acarretando uma maior concentração do ferro e do cromo em seu extrato solubilizado.

\section{DISCUSSÃO}

O estudo realizado em escala de laboratório, através da confecção de corpos de prova, indicou que a formulação mais adequada para a realização do teste de queima em escala industrial para a fabricação de tijolos foi de $90 \%$ da matériaprima convencional (argila) e $10 \%$ da matéria-prima alternativa (borra de fosfato). Os testes físicos realizados nos corpos de prova indicaram resistências mecânicas semelhantes para os percentuais de $0 \%, 5 \%$ e $10 \%$ do resíduo, e valores inferiores para o percentual de $20 \%$. Desta forma, os corpos de prova contendo $0 \%, 5 \%$ e $10 \%$ de borra fo- ram encaminhados para análises físicoquímicas, tendo sido todos eles classificados como Classe II - A (não perigoso e não inerte), em função do resultado do parâmetro alumínio no ensaio de solubilização.

Os resultados dos ensaios de resistência à compressão e absorção de água nos tijolos fabricados durante o teste de queima realizado em escala industrial indicaram que, em termos físicos, não há restriçōes quanto à incorporação de até $10 \%$ do resíduo borra de fosfato na massa cerâmica para a fabricação de tijolos, sendo possível sua comercialização como um bloco cerâmico de vedação classe 10 .

As análises físico-químicas do tijolo contendo $10 \%$ do resíduo borra de fosfato fabricado durante o teste de queima indicaram que o mesmo é classificado como Classe II - A (não perigoso e não inerte), em função do resultado dos parâmetros alumínio, ferro, manganês e cromo no ensaio de solubilização. No entanto, é importante destacar que há grande possibilidade de que esta classificação tenha sido obtida não em função do resíduo, mas sim em função da própria argila. Isto porque a presença de alumínio, ferro e manganês está intimamente relacionada à composição da argila (embora a borra de fosfato também apresente estes elementos na composição de sua massa bruta) e tendo em vista que a concentração de cromo no extrato solubilizado do corpo de prova contendo $0 \%$ de borra foi superior àquela do corpo de prova contendo $10 \%$ de borra de fosfato.

Para que esta suposição seja confirmada, propõe-se a realização de um novo teste de queima para fabricação de tijolos contendo $0 \%$ e $10 \%$ de resíduo. No entanto, para que os resultados de classificação destes tijolos sejam representativos, é imprescindível que os dois tipos de tijolos sejam processados rigorosamente com a mesma amostra de argila, tendo em vista que a sua heterogeneidade poderia mascarar os resultados.

É importante destacar que a presença do ferro e do manganês pode alterar as características físicas da qualidade das águas, incorporando eventualmente cor e turbidez, não caracterizando, no entanto, inconveniência do ponto de vista sanitário. O manganês em sua forma solúvel é, inclusive, utilizado como micronutriente para o solo nas atividades agrícolas.

Ainda, dois outros aspectos deverão ser salientados. O primeiro refere-se à redução da extração de matérias-primas di- 
retamente do meio ambiente e o segundo diz respeito aos benefícios econômicos e sociais. Isto porque a margem de lucro da indústria cerâmica é muitas vezes pequena e a utilização de resíduos em seu processo produtivo poderia ser cobrada.

\section{CONCLUSÕES}

As análises físico-químicas da borra de fosfato gerada na FIAT indicam que se trata de um resíduo Classe II - A (não perigoso e não-inerte), que possui como principais constituintes o ferro, o zinco e o níquel, em função do ataque na superfície metálica das carrocerias e da constituição da mistura ácida do tanque de fosfatização.

De acordo com as análises realizadas nos ensaios em escala de laboratório e em escala industrial (teste de queima), podese concluir que a utilização do resíduo borra de fosfato para a fabricação de tijolos é recomendada em uma proporção de até $10 \%$ do resíduo em relação à argila. Os resultados obtidos neste trabalho indicam que o tijolo contendo $10 \%$ de borra de fosfato não pode ser considerado inerte pelas normas atualmente em vigor, mas tampouco possui características que o tornam perigoso do ponto de vista ambiental. Desta forma, é possível sua comercialização como um bloco cerâmico de vedação classe 10 , de acordo com os resultados físicos obtidos.

\section{AGRADECIMENTOS}

As autoras agradecem a FIAT e Cerâmica Vilaça pelas amostras de resíduo e pelos testes de incorporação do resíduo no processo produtivo, respectivamente.

\section{REFERÊNCIAS}

ASSOCIACÃAO BRASILEIRA DE NORMAS TÉCNICAS. NBR-10004: Resíduos sólidos classificação. Rio de Janeiro, 2004.

ASSOCIAC̄̃̃O BRASILEIRA DE NORMAS TÉCNICAS. NBR-10005: Lixiviação de resíduos - procedimentos. Rio de Janeiro, 2004.

ASSOCIAÇÃO BRASILEIRA DE NORMAS TÉCNICAS. NBR-10006: Solubilização de resíduos - procedimentos. Rio de Janeiro, 2004.

ASSOCIAÇÃO BRASILEIRA DE NORMAS TÉCNICAS. NBR-10007: Amostragem de resíduos - procedimentos. Rio de Janeiro, 2004.

ASSOCIAÇĀO BRASILEIRA DE NORMAS TÉCNICAS. NBR-6461: Bloco cerâmico para alvenaria. Verificação da resistência à compressão método de ensaio. Rio de Janeiro, 3 p. 1983.

ASSOCIAÇÃO BRASILEIRA DE NORMAS TÉCNICAS. NBR-7171: Bloco cerâmico para alvenaria - especificação. Rio de Janeiro, 2 p. 1992.

ASSOCIAÇĀO BRASILEIRA DE NORMAS TÉCNICAS. NBR-8042: Bloco cerâmico para alvenaria - formas e dimensöes. Rio de Janeiro, 4 p. 1992.

ASSOCIAÇÃO BRASILEIRA DE NORMAS TÉCNICAS. NBR-8947: Telha cerâmica determinação da massa e da absorção de água. Rio de Janeiro, 2 p. 1985.

CAPONERO, J. Comportamento da lama de fosfatização no processo de produção do clínquer de cimento Portland. Dissertação (Mestrado em Engenharia Metalúrgica e de Materiais) - Escola Politécnica, São Paulo, SP. 116 p. 1999.

ENBRI. Development of a framework for environmental assessment of building materials and components (ENBRI Proposal to European Community BRITE EURAM Program). 1994.

FEAM - Fundação Estadual do Meio Ambiente. Inventário Estadual de Resíduos Sólidos Industriais do Estado de Minas Gerais. Belo Horizonte, 89 p. 2003
JOHN, V.M. Panorama sobre a reciclagem na construção civil. Revista Limpeza Pública, 53:811, 1999.

NISHINO, T. Recovery of Phosphoric Acid from Waste Phosphate Sludge by Dissolution Using Ion Exchange Resin. Journal of Japan Society of Waste Management Experts, 5:202-208, 1994.

U.S. ENVIRONMENTAL PROTECTION AGENCY (USEPA). http://www.epa.gov/ swerrims/docs/iwg/phosphatefinal - data da consulta: $07 / 2003$

Endereço para correspondência:

Patrícia de Oliveira Giffoni

Rua João de Freitas, 73 Apt $^{\circ} 604$

Santo Antonio

302 I 0-300 Belo Horizonte - MG -

Brasil

Tel: (3I) 3344-9489

E-mail:pgffoni@hotmail.com 